\title{
Sports cardiology: preventing sudden cardiac death
}

\author{
Jonathan A Drezner, ${ }^{1}$ Sanjay Sharma, ${ }^{2}$ Mathew G Wilson ${ }^{3}$
}

The sudden death of an athlete on the playing field remains one of the most striking and tragic events in sport. For the sports physician, the occurrence of an athlete in sudden cardiac arrest is both unforgettable and terrifying. Well-known cases such as Hank Gathers (1990), Marc-Vivien Foé (2003) and Fabrice Muamba (2012), provide graphic examples of an athlete enduring this deadly crisis-collapsed and unresponsive, eyes rolled back, brief myoclonic seizure-like activity and perhaps the presence of agonal respirations as limbs go from rigid to limp. For physicians responsible for the medical care of athletes, a single universal priority should guide our clinical efforts, namely to protect the health and safety of athletes. This journal once again assumes a leading role in the field of sports cardiology by presenting current information relevant to the prevention of sudden cardiac death (SCD) in athletes.

\section{INCIDENCE OF SCD: AT THE HEART OF THE MATTER}

Cardiac screening of young individuals engaged in regular exercise to detect silent yet potentially lethal cardiac disease is universally supported. However, intense debate continues regarding the most effective and feasible method for screening. Central to the development and evaluation of effective prevention programmes is an accurate assessment of the incidence of SCD in athletes. Methodological limitations and heterogeneity have provided a wide range of estimates of the risk of SCD in sport. Harmon and colleagues (see page 1185) present a state-of-the-art review on the incidence of SCD in athletes, carefully examining study methodology and the reliability of reported estimates. This article is the first in a series of state-of-the-art reviews that will be co-published in the

\footnotetext{
${ }^{1}$ Department of Family Medicine, University of Washington, Seattle, Washington, USA; ${ }^{2}$ Cardiovascular Sciences Research Center, St George's University of London, London, UK; ${ }^{3}$ Department of Sports Medicine, Aspetar Orthopaedic and Sports Medicine Hospital, Doha, Qatar

Correspondence to Dr Jonathan A Drezner, Department of Family Medicine, University of Washington, Box 354060 Seattle, WA 98195, USA; jdrezner@uw.edu
}

BMJ specialty journal Heart to highlight key areas in sports cardiology to the broader cardiology community.

\section{ADVANCING THE SCIENCE OF CARDIAC SCREENING}

This issue presents many original investigations that advance the cardiovascular care of athletes. While a standardised personal and family history is widely recommended for cardiac screening in athletes, the actual questionnaires utilised remain largely unstudied. Fudge and colleagues analyse history responses to the Pre-Participation Evaluation Monograph, 4th Edition, and compare to ECG screening in a population of active adolescents and young adults. ${ }^{1}$ In a critically important study, Asif and colleagues examine the psychological impact of cardiac screening to address the assumption that ECG screening causes undue anxiety in athletes (see page 1162). In addition, Tipton explores the increased rate of SCD during open water swimming through his novel theory on autonomic conflict (see page 1134), and Pelliccia discusses whether patients with long QT syndrome can participate in sports safely (see page 1135).

\section{ECG INTERPRETATION: TESTING OUR STANDARDS}

When evaluating the potential value and limitations of ECG screening, it is important to recognise that the total-positive and false-positive rates are largely affected by the criteria selected to define ECG abnormalities. In recent years, interpretation standards to detect life-threatening cardiac conditions in young athletes have undergone several modifications to improve the accuracy of ECG screening. ${ }^{2-4}$ Brosnan and colleagues (see page 1144) test the sensitivity and specificity of the Seattle criteria in a cohort of elite Australian athletes. Exeter and colleagues also investigate the value of using standardised criteria for ECG interpretation in competitive athletes (see page 1167), and Riding and colleagues describe ECG and echocardiographic adaptations in Arab athletes. ${ }^{5}$

\section{EDUCATION IS KEY!}

Prevention of SCD in athletes remains a fundamental goal of the sports and medical communities. Physicians responsible for the cardiovascular care of athletes should be knowledgeable in the physiological cardiac adaptations to regular intense exercise (athlete's heart); the conditions associated with SCD in athletes; and ECG interpretation standards that distinguish common training-related findings in athletes from changes associated with pathological cardiac disorders and the secondary investigations necessary to properly evaluate ECG abnormalities. ${ }^{6-8}$ As a reminder, a comprehensive E-Learning course addressing these areas is freely available at http://learning. bmj.com/ECGathlete. BJSM, along with its partner societies, will continue to emphasise new research and education towards the effective prevention of SCD in sport.

Competing interests None.

Provenance and peer review Not commissioned; internally peer reviewed.

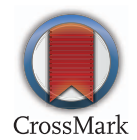

To cite Drezner JA, Sharma S, Wilson MG. Br J Sports Med 2014;48:1133.

Accepted 9 June 2014

Br J Sports Med 2014;48:1133.

doi:10.1136/bjsports-2014-093922

\section{REFERENCES}

1 American Academy of Family Physicians, American Academy of Pediatrics, American College of Sports Medicine, American Medical Society for Sports Medicine, American Orthopaedic Society for Sports Medicine, American Osteopathic Academy of Sports Medicine. Preparticipation physical evaluation. 4th Edn. American Academy of Pediatrics, 2010.

2 Corrado D, Pelliccia A, Heidbuchel $\mathrm{H}$, et al. Recommendations for interpretation of 12-lead electrocardiogram in the athlete. Eur Heart J 2010;31:243-59.

3 Uberoi A, Stein R, Perez MV, et al. Interpretation of the electrocardiogram of young athletes. Circulation 2011;124:746-57.

4 Drezner JA, Ackerman MJ, Anderson J, et al. Electrocardiographic interpretation in athletes: the 'Seattle criteria'. Br J Sports Med 2013;47:122-4.

5 Drezner JA, Asif IM, Owens DS, et al. Accuracy of ECG interpretation in competitive athletes: the impact of using standardised ECG criteria. Br I Sports Med 2012;46:335-40.

6 Drezner JA, Fischbach P, Froelicher V, et al. Normal electrocardiographic findings: recognising physiological adaptations in athletes. Br J Sports Med 2013:47:125-36.

7 Drezner JA, Ashley E, Baggish AL, et al. Abnormal electrocardiographic findings in athletes: recognising changes suggestive of cardiomyopathy. Br I Sports Med 2013:47:137-52.

8 Drezner JA, Ackerman MJ, Cannon BC, et al. Abnormal electrocardiographic findings in athletes: recognising changes suggestive of primary electrical disease. Br J Sports Med 2013;47:153-67. 